\title{
PULSACÕES NO CORACÃO DA CIDADE: cenários de intervenção em centros urbanos contemporâneos
}

\author{
IrlysAlencarF.Barreira"
}

\begin{abstract}
No intuito de ordenar espaços e devolver aos centros urbanos o papel hegemônico perdido, políticas urbanas contemporâneas vêm procurando fomentar diferentes modos de intervenção designados por "revitalização" ou "requalificação". A cidade, voltada para a valorização de seu patrimônio histórico, torna-se então objeto de remodelacões e reformas arquitetônicas, com vistas à preservação, ensejando imagens e marcas. Refletir sobre as intervenções em centros urbanos de metrópoles contemporâneas, incluindo experiências mais recentes realizadas em cidades nordestinas, constitui o objetivo central do presente artigo. Com menos interesse em fazer avaliações propositivas, o artigo analisa concepções e conflitos simbólicos que balizam práticas de "revitalização". A presença de consumidores variados do espaço público (turistas, moradores, comerciantes etc.) e as polêmicas estabelecidas em torno dos investimentos culturais e econômicos servirão de baliza para as ideias presentes no texto.

PALAVRAS-CHAVE: centro urbano, "revitalização”, espaço público, turismo, metrópole.
\end{abstract}

Os centros urbanos cada vez mais aparecem como expressão de zonas emblemáticas de cidades. Evocam o passado, momento no qual desepenhavam o papel de agregar funções administrativas e comerciais importantes, reportandose também a um futuro e ao presente indefinidos quanto a possíveis formas de utilização de equipamentos e espaços considerados "históricos".

De fato, a ideia de centralidade parece anacrônica face à tendência atual de a maioria das cidades se tornarem policêntricas, sem um lugar convergente de funções sociais. Se, em determinado momento da história das urbes, o centro era percebido e vivido como um espaço de convivência coletiva, as próprias definições topográficas atuais, definindo os limites onde começa e termina essa zona, são complexas, repercutindo sobre o sentido do lugar atribuído por seus moradores. ${ }^{1} \mathrm{~A}$

* Doutora em Sociologia. Professora titular de Sociologia do Programa de Pós-Graduação em Sociologia da Universidade Federal do Ceará. Bolsista de produtividade em pesquisa do CNPq.

Universidade Federal do Ceará, Centro de Humanidades. Av da Universidade, 2995. Cep: 60020-181. Benfica Fortaleza - Ceará - Brasil. lepec@ufc.br

${ }^{1}$ Informantes de uma pesquisa sobre moradia, realizada em Fortaleza, no contexto da disciplina Sociologia Urba multiplicidade de centros exprime as características atuais de metropoles, tornando-os muitas vezes desconectados entre si e postos em disputa pela hegemonia de atividades sociais. Refiro-me, particularmente, às funções de comércio e serviços, hoje difundidas em múltiplas áreas do espaço urbano.

É notório observar que intervenções realizadas em várias cidades contemporâneas caracterizam-se pela busca de conferir aos locais públicos formas dinâmicas de utilização, baseadas em investimentos comumente associados a comércio e lazer. Nessa direção, os espaços públicos passam a ser alvos de projetos que visam a "recuperar zonas degradadas", imprimindo-lhes outras alternativas de utilização, oscilantes entre a afirmação de sentidos arcaicos e a incorporação de novos usos a antigas edificações.

As expressões "requalificação" ou "revitalização", ${ }^{2}$ utilizadas para traduzir a tentativa de dinana, ministrada por mim, em 2008, demonstraram dificuldades em se definirem como "moradores do centro" ou "moradores de área próxima ao centro".

${ }^{2}$ A respeito da terminologia utilizada como referência nas práticas e concepções de intervenção nos centros urbanos ver: "Re: atrás de, depois de...” (Vasconcellos; Mello, 2006). 
mizar antigas áreas centrais, readaptando-as a funções do presente, são recorrentes em discursos de gestores e profissionais do urbanismo, ensejando planos e propostas de mudança na zona considerada como o "coração" da cidade.

No intuito de ordenar espaços e devolver ao centro o papel hegemônico perdido, as políticas urbanas contemporâneas vêm procurando fomentar ações culturais diferenciadas. Representações baseadas em supostos memorais confirmam lugares emblemáticos, acionando narrativas baseadas na ideia de um processo urbano a ser preservado. A cidade voltada para a valorização de seu patrimônio histórico torna-se, então, objeto de remodelações e reformas arquitetônicas, com vistas à preservação, ensejando imagens e marcas (Vaz, 2008).

Refletir sobre algumas intervenções em centros urbanos de metrópoles contemporâneas, incluindo experiências mais recentes realizadas em cidades nordestinas, constitui o objetivo central do presente artigo. Menos interessada em fazer avaliações propositivas, pretendo analisar concepções e conflitos simbólicos subjacentes a tentativas de "revitalização". A presença de consumidores variados do espaço público (turistas, moradores, comerciantes, etc.) e as polêmicas estabelecidas em torno dos investimentos culturais e econômicos servirão de baliza para as ideias presentes no texto.

\section{PRESERVAÇÃO E TRANSFORMAÇÃO: a idealização do espaço público}

O princípio de "revitalização" dos centros históricos e a instauração de pontos turísticos são comuns à considerável maioria das metrópoles brasileiras. O crescimento urbano das cidades e as de tentativas concomitantes de preservação de áreas consideradas decadentes aparecem, nesse sentido, acompanhados de investimentos materiais e simbólicos em torno da manutenção de equipamentos com vistas a proteger aquilo que é designado como patrimônio.

Observa-se, no intento das reformas e na definição de zonas históricas urbanas, atuações baseadas em concepções variadas. Algumas caminham na direção de animações culturais, incluindo modelos de preservação de teor arquitetônico associados à dinamização econômica do local. Investimentos em moradias antigas, construção de novas e oferta especiais de serviços e lazer pontuam parte significativa das experiências que se efetivam em metropoles contemporâneas.

O circuito das ações em torno de politicas urbanas não navega em águas tranquilas. Polêmicas referentes a empreendimentos efetivados em locais "degradados" emergem com intensidade, pondo em pauta concepções sobre o espaço público e sentidos atribuídos ao que e classificado como patrimônio histórico. É sob o signo da mudança e da preservação que ações materiais e simbólicas passam a pautar politicas urbanas, envolvendo agentes governamentais, especialistas e profissionais do urbanismo.

A experiência de reabilitação do Centro Histórico de Recife ${ }^{3}$ traz elementos importantes para se pensar sobre intervenções e usos do espaço urbano associados ao tema da requalificação.

O plano estratégico de reabilitação do centro da capital pernambucana foi elaborado por arquitetos e urbanistas ligados ao governo Jarbas Vasconcelos (PSDB). As concepções que animaram a proposta reconheciam a necessidade da interferência dos poderes publicos visando à reabilitação do lugar, incluindo a participação dos moradores como instrumento importante de ação política. O documento que serviu de base à proposta criticava o processo gradativo de comercialização do local, opondo à atividade de consumo a necessidade de "apropriação do espaço público" para fins multifuncionais, incluindo o reforço à moradia.

O projeto "memória em movimento" firmava seu objetivo na integração dos moradores às mudanças em curso, considerando a necessidade de solidificar ações menos voltadas para o estímulo de atividades de consumo e mais interessadas na manutenção de moradias. Havia o suposto de que as postitutas e portuários tinham assegurado, por conta

As informações sobre a experiência de Recife estão baseadas fundamentalmente no livro de Leite (2007). 
de sua permanência no local, a preservação dos monumentos antigos. Eram, portanto, atores relevantes na constituição da ideia de patrimônio.

Múltiplas iniciativas foram viabilizadas por meio do projeto "memória em movimento": a recomposição da história do bairro por meio de entrevistas com antigos moradores, a valorização da habitação à moda modelo de Bolonha e a defesa do uso da moradia para camadas populares, sem abdicar, no entanto, da utilização da área para fins turísticos.

A implementação posterior do projeto de "revitalização" foi efetivada por meio de fases que incluíam assistência à população carente de saúde e educação, tornando-se símbolo de uma aliança entre governo estadual e municipal ${ }^{4}$ (Leite, 2007).

Tratava-se de uma proposta flexível, executada em continuidade, com objetivos precisos de transformar o bairro de Recife em Centro Metropolitano. A ideia era a de torná-lo modelo de espaço público e local de atração turística nacional e internacional.

Em que pese sua singularidade, o projeto de revitalização do Centro de Recife repetiu uma tendência que proliferou nas últimas décadas, em metrópoles brasileiras e nordestinas, referente à transformação de áreas marginais em complexos centros de lazer. As descontinuidades entre as propostas voltadas para o plano de devolução ao local da vitalidade perdida e as práticas efetivas de uso do espaço emergiram, no entanto, no decorrer do tempo.

No primeiro momento de reabilitação, as noções de espaço público e cidadania encontravam-se enfatizadas, mesmo genericamente, conferindo sentido político ao plano de remodelação urbana. Sua concretização reforçaria as atividades de lazer e consumo, acionando mais fortemente o controle sobre os usos do espaço.

Posteriormente, as experiências de inserção dos moradores tornaram-se escassas, prevalecendo a ideia de espetáculo e as tensões entre usos “devidos" e "indevidos". Percebe-se, portanto, que a reconhecida dinamização do espaço público ati-

${ }^{4}$ Refiro-me à aliança entre o prefeito Joaquim Franciso (PFL) e o governador Jarbas Vasconcelos (PMDB). vou polêmicas sobre os temas do "esvaziamento", a presença descontínua de visitantes e as dificuldades de permanência de moradores. Discussões sobre a possibilidade de as políticas de patrimônio incorporarem usos locais emergiram nesse momento, repondo a pauta das tensões entre ocupação e legitimação de zonas requalificadas. Trata-se de uma situação também presente em outras experiências de remodelação urbana.

Em São Luís, ${ }^{5}$ o processo de investimento no Centro Histórico foi reforçado em 1997, ocasião na qual a cidade era incluída na linha de patrimônio mundial pela Unesco. Os primeiros trabalhos sobre o levantamento do acervo arquitetônico e artístico partiram de reforços promovidos por essa instituição, contando com interferência do arquiteto francês Michel Parent, também indicado para realizar relatório junto à Unesco sobre o Pelourinho em Salvador. O Plano Municipal de Gestão do Centro histórico foi adotado pela Prefeitura de São Luís, incluindo modelos de circulação viária e valorização do patrimônio imobiliário por meio da indução de usos habitacionais, culturais e turísticos.

A tentativa de incorporar à proposta de "revitalização" práticas sociais diferenciadas e não restritas à oferta de espetáculos reconhecia a necessidade de equacionar, de modo equilibrado, as funções do passado e do presente. O turismo foi um objeto considerado relevante nesse arranjo complexo de ideias e ações, como reconhecida atividade de animação do espaço público.

Não obstante a tentativa de controle dos usos do espaço, explicitada nos critérios adotados para a preservação do Centro Histórico da cidade de São Luís, os investimentos na área de comércio e serviços potencializaram o declínio do Centro como espaço de moradia. A política patrimonial produziu, portanto, efeitos mais proeminentes no setor de serviços e comércio, que passaram a pautar-se principalmente pela oferta de bens culturais considerados "típicos" da capital maranhense. Sem desconsiderar a importância de intervenções esté-

${ }^{5}$ As informações sobre São Luís foram baseadas fundamentalmente em Espírito Santo (2006). 
ticas e culturais que vabilizaram a efervescência do Centro Histórico da capital maranhense, observa-se que a relação complexa entre usuários, visitantes e moradores permanentes apareceu com nitidez. Destaca-se assim, em São Luiz, dificuldades comuns a outras cidades nordestinas atuais, referentes ao equilíbrio da oferta de bens de lazer, consumo e moradia nas áreas consideradas históricas.

Reflexões sobre a necessidade de reforço ao patrimônio histórico do centro de Fortaleza foram também retomadas à luz de propostas de "requalificação". Discursos sobre a necessidade de conservação de espaços e monumentos apontaram a necessidade de resguardar o Centro da Cidade e conservar a sua "história". Revitalizar o decadente e preservar o antigo vem portanto, ao longo do tempo, se constituindo em lema de gestores ou planejadores urbanos, preocupados em reverter processos de transformação característicos hoje da maioria das metrópoles.

Uma das propostas discutidas em vários projetos que visam a dinamizar o centro da Capital Cearense é a de aproveitamento de moradias para as famílias de classe média. A hipótese de criação de corredores culturais, facilitando passagens entre pontos importantes, permitiria a valorização de equipamentos públicos, tais como o antigo Parque da Cidade e sua ligação com a Praça José de Alencar, que abriga o teatro mais importante de Fortaleza.

O Centro de Fortaleza viveu diferentes momentos de intervenção. A remodelação da Praça do Ferreira, ocorrida em 1991, baseava-se na tentativa de manter a "história do local" sem abdicar dos novos usos. O projeto arquitetônico levou em consideração a reforma de antigos monumentos e prédios, incrementando o aproveitamento de espaços capazes de restaurar e incentivar formas variadas de sociabilidade. A possibilidade de ampliar e recuperar o espaço de moradia continua no horizonte de algumas propostas cuja importância justifica-se diante da perda gradativa de habitabilidade no local. Denota se que em que, em menos de 10 anos, segundo um estudo feito pela Habitafor, 5.904 habitantes deixaram de residir no centro. Em 2000, conforme dados do IBGE, havia 24.775 habitantes; em 1991, 30.000 (Cf. Jornal $O$ Povo, 7/02/2009).

As polêmicas mais recorrentes a respeito do Centro de Fortaleza gravitam em torno da presença do comércio ambulante e categorias sociais consideradas expressões da desordem e da violência. ${ }^{6}$ Ao longo do tempo, o Centro tornou-se, de fato, um local de presença quase exclusiva de classes populares, não obstante as tentativas mais recentes de programas de animação cultural que visam a assegurar a frequência da classe média no local.

A criação de áreas contíguas à zona central de Fortaleza, como o Centro Dragão do Mar de Arte e Cultura, objetivava inserir a cidade no contexto de reformas gerais, impedindo que a área reproduzisse o processo de verticalização em curso (Gondim, 2006). O projeto original contemplava a ampliação das áreas de intervenção, que deveriam integrar a Praia de Iracema ao centro da cidade. Essas reformas, que se efetivaram concomitantemente a mudanças espaciais mais recentes - exemplificadas na verticalização, na instituição de áreas "nobres" e na definição de zonas consideradas "históricas"-, produziram, simultaneamente, polêmicas entre moradores e consumidores visitantes (Barreira, 2007).

Outra experiência significativa de intervenção realizada com vistas a consolidar o patrimônio histórico local ocorreu no Centro Histórico de Salvador, ${ }^{7}$ tombado pela Unesco em 1985. Nesse intuito de preservação, o reforço à arquitetura colonial bem como o realce de tradições culturais foram fundamentais para a produção de um padrão turístico. Os processos consequentes de expulsão da população, vigentes desde 1967, foram complexos, apontando saídas de moradores asseguradas por meio de indenizações (Berdoulay; Paes, 2008).

Os conflitos entre o reforço ao fluxo turísti-

${ }^{6}$ Segundo dados da Secretaria do Centro, Fortaleza possui 981 ambulantes com termo de permissão distribuídos nos passeios e praças da área. No "beco da poeira”, nome atribuído à localidade próxima ao centro que, nesse momento, acabou de vivenciar processo de transferência, alojavam-se 2080 permissionários regularizados.

7 As reflexões sobre a experiência de Salvador foram obtidas, fundamentalmente, por meio do artigo de Berdoulay, Vincent; Paes Maria Tereza Duarte "Imagem e patrimonialização em planejamento urbano: Salvador (Bahia) e Bourdeaux em perspectiva” (2008). 
co no Pelourinho, com a valorização estética da paisagem, em contraponto à ideia de espaço para moradia, são considerados emblemáticos. A primazia conferida à refuncionalização turística não eliminou uma subversão de territorialidades locais, como o comércio de produtos típicos baianos e a oferta de outros serviços construídos nas brechas da legalidade. O programa de recuperação do Centro Histórico de Salvador, inaugurado em 1992, passou por várias etapas. A primeira fase compreendeu a implantação de um centro comercial turístico próximo ao Pelourinho. Os imóveis foram ocupados por comércio, atividades culturais e negócios ligados ao turismo.

Estratégias outras, que buscavam a diversificação de atividades, foram implementadas com auxílio do Programa de Desenvolvimento do Turismo (Prodetur). A concepção do plano de reabilitação do Centro Antigo de Salvador, que envolveu Governo do Estado, Prefeitura, Ministério do Planejamento e Instituto do Patrimônio Histórico, teve por objetivo coordenar, de forma mais integrada, as diversas intervenções e projetos em curso. A criação do quarteirão cultural permitiu a diversificação do público de visitantes.

Recentemente, a preocupação com a permanência da população no Centro de Salvador ressurge mais fortemente, considerando-se a sua importancia para a continuidade temporal do empreendimento, não assegurada pela presença exclusiva do turismo. O programa Monumenta do Ministério da Cultura, que prevê usos mistos e residenciais para áreas de preservação, além do restauro integral de imóveis importantes, vem constituindo um reforço na consolidação de equipamentos urbanos multifuncionais.

Observa-se, nas experiências mencionadas, que a equação moradia versus investimentos em áreas de comércio, turismo e lazer estão postas com nitidez, pontuando conflitos simbólicos em torno do tema do espaço público. Moradores, turistas e visitantes ocasionais expressam não só frequencias diversificadas, mas modos diferenciados de consolidar e conceber as políticas de patrimônio. É sintomático observar que, não obstante as diferen- ças históricas e econômicas peculiares a cada experiência, existe um padrão que se torna quase um modelo. Trata-se da questão da dinamização de áreas que subvertem as formas originais de uso do espaço urbano, submetidas a operações de requalificação indutoras de outras formas de segregação social.

\section{ESPAÇO PÚBLICO, PARA QUAL PÚBLICO?}

Sennett, em livro polêmico intitulado $O$ declínio do homem público (1999), chama a atenção para o desaparecimento gradativo de experiências compartilhadas em espaços urbanos marcados pela lógica da evitação e reforço ao individualismo. Argumenta o autor a prioridade atualmente conferida à visão íntima da sociedade, sendo o mundo impessoal dos encontros anônimos considerado decepcionante e vazio. A crítica de Sennett fundamenta-se na necessidade de uma lógica da diversidade, capaz de permitir a vigência de experiências coletivas peculiares à própria ideia de cidade. A teatralidade da vida social, implicando a presença de atores e papéis desempenhados no espaço público, viabilizaria o cumprimento das regras do viver citadino.

Em uma outra perspectiva, baseada na ideia do espaço público como esfera de ação política, Habermas (1984) chama a atenção para a cidade como um local de encontro entre concepções e práticas diferenciadas. O sentido do público como lugar de troca de experiências subsidiaria um ideal de convivência urbana entre diferentes, gradativamente subtraído pela lógica do consumo e a hegemonia do poder.

Os processos de ativação do espaço público, materializados em intervenções pontuais aqui rapidamente dscritas, parecem manter pouco diálogo com noções de diversidade e frequencia de consumidores. De fato, a própria ideia de público e o tipo de consumo encontra-se em questão.

Foi nos moldes de uma redefinição e permutabilidade dos locais de moradia, comércio e lazer que se realizou a ideia de recuperação de 
“zonas históricas” de cidades. Nessa direção, o centro de cidades passou a constituir um dos locais de produção de práticas culturais e políticas baseadas em evocações à memória, simbolizando a ideia de um espaço público a ser ativado e reconstruído.

No intuito de construir uma articulação harmoniosa entre passado, presente e futuro, os investimentos comerciais e culturais vêm integrando estratégias múltiplas. Rituais como o carnaval, festas populares, animação de praças e eventos cívicos buscam dinamizar antigos usos do espaço urbano, associados a formas contemporâneas de consumo. Propostas recentes de reforma de centros citadinos procuram, assim, conjugar interesses comerciais e turísticos, almejando a frequência da classe média como garantia de sustentabilidade dos empreendimentos.

As interferências em centros urbanos evocam a utopia da convivência coletiva, acenando com possibilidades de recompor espaços "esvaziados". A ideia de "devolver a cidade aos moradores" passa a ser veiculada com frequência em vários dicursos, sendo as operações e reformas realizadas em nome da virtualidade de uma história urbana a ser protegida.

Perspectivas mais amplas e recentes, designadas por "globalização", trouxeram referentes novos para pensar sobre as cidades, elegendo a cultura como elemento de ativação e manutenção de sociabilidade. Situações de homogeneidade e heterogeneidade foram também retomadas sob o ângulo das dinâmicas culturais citadinas, marcadas pela permanente busca de valorização das identidades locais (Canclini, 1998).

No quadro das interações multiculturais, o turismo entrou como variável importante de observação de uma produção ativa de lugares, competindo na busca de qualidades especiais e no esforço de formar uma imagem distintiva das cidades. $\mathrm{O}$ culto ao "diferente" e ao "exótico" foi priorizado em análises voltadas para a constituição de narrativas e paisagens urbanas (Fortuna, 1999).

As novas formas de segregação espacial, não restritas ao tema das desigualdades econômicas, ressurgem ao lado de conflitos simbólicos, alimentados na contenda entre lugares e memórias. A cidade cosmopolita, como palco de inúmeras intervenções urbanas, promoveu uma reflexão sobre os temas do patrimonio cultural, incluindo a delimitação e o uso dos espaços, as classificações e sentidos elaborados no cotidiano de práticas de atores sociais: moradores, comerciantes, visitantes etc.

Os investimentos urbanos, projetos e discursos que acenam com a preservação do patrimônio, ligam-se a um processo que pode ser nomeado de "invenção das tradições" (Hobsbawm), presente em narrativas e ícones que buscam recompor a origem e o crescimento de cidades.

Ochamado "esvaziamento" de espaços urbanos convoca uma reflexão sobre a própria ideia de usos ou apropriações de áreas públicas. Certeau (1994), observando a característica diversificada do consumo urbano, para além das classificações hegemônicas, considera que o próprio viver na cidade é sinalizador de uma variabilidade de práticas sociais ou usanças, expressivas da dimensão criativa e relacional propiciada por moradores ou visitantes.

Na realidade, o uso dos espaços na cidade não se separa de processos, conflitos e intervenções políticas nos quais se percebe a emergência de atores no fluxo das diferentes dinâmicas interativas. A cidade, nesse sentido, é múltipla, não obstante sua capacidade de "se impor" a seus moradores e visitantes, constituindo-se em uma espécie de unidade imaginária -identidade a partir da qual cada aglomerado urbano pretende afirmar sua marca distintiva.

Reflexões sobre a vida urbana contemporânea supõem, entre outras abordagens, uma observação que capte os investimentos políticos para dar forma à cidade, articulados a disputas simbólicas pelo uso e apropriação dos espaços. A cidade, como totalidade e com suas materialidades plurais, trazem referentes importantes tanto para se pensar na expansão comum às metrópoles, como nos territórios específicos oriundos de cada localidade urbana. Em tal perspectiva, as cidades, assim como os bairros, trazem as marcas de seus atores, o fluxo das interações descontínuas e das 
sociabilidades conflitivas (Simmel, 2004).

Na medida em que a construção do patrimônio emerge na direção da visibilidade turística, a narrativa da cidade torna o "passado" a ser apresentado objeto de recriação ou inventividade. Novas funções para velhos equipamentos e controle sobre "usos indevidos" configuram parte significativa das políticas e dos investimentos culturais e comerciais. Nunca é demais lembrar que as narrativas da cidade são também narrativas para o consumo. A esse respeito, observa se que a hipervalorização de espectos estéticos do patrimônio sobrepõe-se ainda mais frequentemente aos interesses e necessidades das populações ocupantes de áreas protegidas. Arantes (2009, p.20) assevera que uma das possibilidades de entrada para o tema da inserção do patrimônio nas cidades é por meio do conceito de patrimônio sustentável urbano, que se associa à ideia de conservação integrada de centros históricos. Essa perspectiva estaria incorporada a significados e valores reconhecidos pelos habitantes da cidade, implicando usos efetivos e formas de apropriação do espaço. Ressaltam-se, assim, "os sentidos de lugar que nutrem a experiência de habitar as cidades e o constante refazer das identidades no espaço urbano (Arantes, 2009, p.18).

No âmbito das questões referentes a políticas de patrimônio, é importante verificar concepções e práticas que subsidiam a "requalificação" de espaços urbanos. O coordenador do serviço de patrimônio em Lyon, Bruno Delas, ${ }^{8}$ considera que uma das características de cidades latino-americanas é a dificuldade de envolvimento dos habitantes no processo de elaboração da memória. O profissional do patrimônio comentou o esvaziamento do Pelourinho em Salvador, considerando-o exemplo da dificuldade de permanência dos habitantes no local a ser preservado. Segundo ele, a convenção que regulariza o tema do patrimônio mostra a responsabilidade das ações e os critérios de ordem ética e moral que não devem ser fundamentados apenas com base na antiguidade do lo-

${ }^{8}$ Entrevista concedida à autora em 2004, no âmbito do acordo Capes/Cofecub, envolvendo Universidade Federal do Ceará e Université Lumiére Lyon II. cal. Delas aponta a necessidade de renovação de uma filosofia atualizada da cidade, considerando que "ela não e um museu, mas um ato de criação arquitetural". Na visão do chefe de serviço do patrimônio, seria preciso também encontrar novas formas de uso para locais e equipamentos anacrônicos, por meio da ativação de outras funções emergentes. Nesse sentido, indaga: como restaurar uma antiga igreja ou hospital que não têm mais a mesma utilidade do passado?

O risco de "esvaziamento do centro" presente em Lyon é analisado por Authier (2003), tendo como referência a gentrificação do antigo bairro Saint Georges. Verifica o pesquisador a convivência de mobilidades diferenciadas, típicas de zonas centrais citadinas, nas quais ondas sucessivas de instalação da população mobilizam parcelas diferentes das classes médias.

Em Lyon, propostas de uso do espaço, incorporando segmentos sociais em busca de alternativas de moradia e incluindo a presença de camadas médias, antecedem a intervenção do poder público. A retomada social do bairro de Saint Georges vem ocasionando a presença mais numerosa de moradores transitórios, reforçando o risco da divisão social. Diferentes concepções sobre a utilização do bairro caracterizam a ocupação mais recente do local. Observa Authier que, enquanto os operários revelam desinteresse no lugar de moradia, os estudantes e os executivos, identificados com a proposta de revitalização, têm forte ligações com o bairro. O fato é que a identificação entre moradores e local de moradia incorpora temas como funcionalidade, moda, investimento econômico etc, acionando um complexos de ações quase sempre não-convergentes.

O tema do "esvaziamento" ou acréscimo de novas funções ao centro de cidades pode também ser observadoem Barcelona. OCentro Antigonãofoiabandonado pela classe média, embora sua presença esteja restrita a alguns lugares (Claver, 2003). A pesquisadora observa que o papel da intermediação pública foi determinante para o plano de "revitalização", contando com a participação de diferentes atores sociais. A pressão dos movimentos sociais urbanos por 
mudanças na periferia, ocasionada pelo processo de redemocratização, repercutiu sobre a versão do "centro degradado", que é exemplificado na multiplicação de bares e na presença de prostituição. Em fins dos anos 1970, houve a refuncionalização de zonas, separando-se áreas comerciais e residenciais, interferindo a prefeitura no incremento espaciais de cultura e zonas comerciais alternativas. A diversificação no uso do espaço público em Barcelona reproduziu, no entanto, os riscos de novas formas de segregação e conflito entre usos do espaço.

Esse conjunto de experiências põe em questão o dilema dos conflitos simbólicos que se efetivam em torno do uso do espaço público, tornando os centros históricos uma espécie de termômetro das transformações urbanas que vêm se processando em metrópoles nos últimos vinte anos. Destacase, nessa perspectiva, o alerta já enunciado por Jacobs (2000), sobre a necessidade da articulação ente dinâmicas e diversidades como suportes fundamentais para a valorização e renovação de cidades. É importante não destruir o quadro das trocas tradicionais, assevera a estudiosa dos espaços de intervenção urbana. Os centros históricos repõem, justamente, o drama da dinamização e preservação da vitalidade, criando tensões entre frequentadores $\mathrm{e}$ modos de apropiação do espaço.

Subjacente aos usos e apropriações do espaço que fundamentam a polêmica do "esvaziamento", entra em jogo a presença do capital simbólico e comercial.

\section{DESAFIOS DA INTERVENÇÃO: capital simbó- lico versus capital economico}

Pensar o centro como patrimônio evoca o sentido de passado e conservação. Supõe a urgência de cuidar de "algo que precisa ser preservado e está em risco de extinção”, tendo em vista a destruição de antigos imóveis, a presença de atividades e usuários considerados indesejados, a transferência de estabelecimentos importantes de comércio para outras localidades etc. Todas essas ações são percebidas como sintomas de "desvitalização" e ameaça ao patrimônio público. Sabe-se, no entanto, que bens materiais, ao longo do tempo, são passíveis de novos usos, e é justamente a transformação de funções e de formas de ocupação que desafia o discurso da preservação e dos conflitos de classe aí embutidos, a exemplo dos cortiços em São Paulo (Kowarick, 2009).

Parte significativa dos argumentos de profissionais do contexto urbano, assim como de gestores públicos, baseia-se na existência de um potencial econômico, cultural e comercial "pouco aproveitado", o que deixa essa zona suscetível à deterioração e ao "esvaziamento". É caminhando nessa direção que políticas de intervenção urbana em centros históricos elegem essa zona como contexto privilegiado de investimentos legítimos, porque considerados salvaguardas da memória e dos sentidos de totalidade da metrópole.

De fato, desde o momento em que as cidades se tornaram policêntricas, com redistribuição de funções comerciais e administrativas, acompanhadas de afastamento das classes mais favorecidas para zonas mais distantes, o antigo centro perdeu credibilidade e passou a a abrigar formas de ocupação consideradas problemáticas. Projetos e intervenções voltadas para conter o "esvaziamento" ou regular formas indesejadas de ocupação integram fortemente a agenda de políticos e gestores.

O centro da cidade é também visto como lugar histórico, no qual se desenvolvem as funções básicas de negociação e troca. É a construção de outros polos de aglutinação de atividades que contribui para a difusão da ideia de "vazios", fazendo emergir a seguinte questão: são os centros vazios ou ocupados de forma considerada indesejável? Em Fortaleza, por exemplo, a ideia de "esvaziamento" está associada à presença ou ausência da classe média. Assim como se diz que o espaço está "vazio" porque não é mais frequentado pela classe média, também se diz que a área está "misturada" quando setores populares mais ou menos integrados à vida citadina asseguram uma presença mais evidente. Ressalta-se, portanto, nessa situação, o princípio de dupla segregação que envolve classes populares e as camadas superiores, 
já enunciada por Preteceille no estudo da metrópole parisiense (2003).

Confundindo-se com a ideia de espaço público, o centro das cidades também torna latente o conflito de classes ou a contradição entre funções e modos de utilização da área. É na perspectiva de um sentido de "esvaziamento" do centro, na crítica à "invasão" dessa localidade por vendedores ambulantes e nas outras formas de ocupação desse espaço, que as tentativas de intervenção, assim como os debates acadêmicos e jornalísticos, passam a se efetivar com nitidez. Camelôs, prostitutas e consumidores de drogas corporificam presenças "espúrias", consideradas símbolos da "degradação" e da perda de credibilidade do local.

Se a ideia de "requalificação" presente na maioria das proposições de reforma urbana prima pela valorização simbólica de espaços, instituindo narrativas com atribuições positivas dirigidas a zonas consideradas representativos da cidade, supõe também novos investimentos imobiliários, tendo em vista atrair a presença da classe média. É nessa perspectiva que a cultura e o lazer aparecem como suportes fundamentais do binômio mudança e preservação. A valorização de um público indefinido, o que aflui à cidade em momentos episódicos (turistas) passa também a contar na lógica das tentativas de intervenção, aproximandose de um urbanismo destinado a uma população flutuante, disposta ao consumo de "produtos culturais, fabricados, empacotados", tal como pensou Choay (2001, p.211), referindo-se aos caminhos enfrentados pelas políticas de patrimônio.

A manutenção e reativação de centros históricos traz consigo uma disputa entre diferentes formas de valorização do capital simbólico, posto em sintonia ou conflito com o capital econômico. Assegurar a manutenção de moradores, reforçar a presença de classes mais abastadas, de modo a definir um padrão de consumo, ou investir sobre o incremento do turismo, constituem opções que se colocam permanentemente em confronto.

Por esse motivo, não há como tratar das experiências de dinamização dos centros históricos sem considerar a problemática das desigualdades sociais que interferem sobre os usos, apropiações do espaço e sentidos de patrimonialização. Não deixa de ser sintomático que cidades nordestinas tenham utilizado investimentos turísticos por meio do Programa Prodetur, com vistas a angariar dividendos econômicos, compensatórios de uma situação de pouca industrialização e crise fiscal. A dificuldade de sustentabilidade de experiências vem, portanto, da dependência do turismo como forma quase exclusiva de dinamização de áreas urbanas. ${ }^{9}$ Mesmo na situação de Salvador, cujo crescimento acelerado revelou-se superior ao de outras cidades nordestinas na última década, ocorre uma reconfiguração de territórios voltada para incremento do turismo, com investimentos em eventos culturais e enobrecimento de áreas, visando à difusão de uma imagem positiva da cidade. ${ }^{10}$

A natureza dos investimentos associados a modos diferenciados de consumo também interfere na destribuição, classificação e usos do espaço. Experiências baseadas no reforço ao lazer e à cultura, aí incluindo cenários "históricos" de visitação, empreendimentos diretamente associados à presença de visitantes sazonais, episódicos ou permanentes, têm implicações sobre a sustentabilidade dos empreendimentos.

Quando pesquisadores da Europa, Estados Unidos e América Latina discutem os efeitos de tentativas de requalificação nas áreas centrais, referindo-se principalmente à expulsão de camadas pobres, outros analistas refletem sobre o "esvaziamento" de centros por conta da retirada de funções administrativas e comerciais, transferidas para outras regiões da cidade (Zachariasen, 2006).

As transformações atuais vividas nas urbes contemporâneas ensejam, nesse sentido, discursos frequentementealusivos a diferentes temporalidades. Nesse contexto, o espaço e a vida urbanos aparecem como se fossem submetidos a sucessivas per-

${ }^{9}$ Livramento M. observa que, no Brasil, particularmente no Nordeste, desde o final dos anos 1980, a atividade turística efetivada com recursos da Prodetur vem se associando a políticas públicas locais de natureza desenvolvimentista.

${ }^{10}$ Para uma análise aprofundada da dinâmica metropolitana e estrutura socioeconômica em Salvador, ver Carvalho; Almeida; Azevedo, 2001. 
das que remontam à nostalgia de um tempo anterior de maior sociabilidade e intimidade com a metrópole. Tempo no qual era possível ter controle sobre os processos de mudança.

Percepções sobre o que é considerado histórico, com repercussões sobre a valorização de monumentos e equipamentos, em detrimento da moradia, induzem a formas efêmeras ou transitórias de consumo, contribuindo para o chamado "esvaziamento". Nesse sentido, políticas variadas de intervenção, que se tornam objeto especulação em diferentes cidades, têm em comum a tentativa de dar unidade espacial e temporal a vivências descontínuas que caracterizam as metrópoles submetidas a processos de expansão, segregação.

Os pressupostos das reflexões contidas neste artigo partiram da compreensão da cidade em sua feição dinâmica e plural - resultado de investimentos, usos diferenciados do espaço e disputas simbólicas mediadas por discursos ou narrativas. Para além de um ideal de unidade, a cidade representa a conjunção de dinâmicas sociais. O risco de essencialização ou substantivação do espaço urbano existe quando pensamos a metrópole de modo estático e uniforme. Trata-se de um senso contrário à sua dimensão plástica, moldada por práticas e interações - projeção, no espaço, das relações sociais, tal como pensou Lefebvre (2000) em inúmeras de suas reflexões sobre a perspectiva relacional dos habitantes das cidades modernas.

Os centros históricos podem ser vistos como espaços de idealização a participar de uma produção representacional e imagética não necessariamente condizente com uma política urbanística orientada para investimentos de longo prazo. Imagens sem conteúdo, em muitas situações, caracterizariam o marketing das cidades, com a criação de hipercentros que se assemelham a liftings e outras cirugias plásticas (Peixoto, 2008). O pesquisador, observando experiências em cidades portuguesas, conclui que os centros históricos mais coloridos e mais animados não necesariamente adquirem mais vida própria, criando a distância entre imagem difundida e seu conteúdo.

O conjunto de intervenções discursos e depoimentos, formadores de opinião sobre os processos urbanos contemporâneos, caracterizam o que venho nomeando de "diálogo entre passado e presente”. Entendo diálogo não como relação cordial entre temporalidades, mas apropriações do passado acompanhadas de investimentos materiais e simbólicos considerados expressivos do patrimônio local. Trata-se de uma metáfora que visa a apontar as diferentes formas de evocar o passado, visto tanto sob a óptica de um tempo mítico e sem retorno, como também vivido em continuidade com os usos contemporâneos do espaço urbano. Com isso quero dizer que a "história ou memória da cidade”, materializadas no conceito de patrimônio, expressam versões diferenciadas ou visões de um imaginário ${ }^{11}$ urbano nem sempre convergentes.

A perspectiva de acenos à "revitalização" supõe a possibilidade de construção de liames temporais dotados de narrativas múltiplas. Os apelos turísticos, as intervenções urbanísticas ou as projeções arquitetônicas buscam, cada qual a seu modo, fortalecer a chamada "identidade urbana", guardando o seu quinhão de passado. É nesse âmbito que a ideia de patrimônio suscita uma espécie de afinidade eletiva com a noção de mito, que "tem à sua disposição uma massa ilimitada de significantes" (Barthes, 1989, p.141).

Os discursos construídos sobre a cidade, associados a diferentes práticas sociais, expressam diferentes momentos históricos e experiências. Uma negociação ou conflito entre os espaços que se preservam e os que se modificam indica o estabelecimento de conexões que vão adquirindo matizes diferenciadas, conforme as políticas de intervenção urbana e o poder de imposição, parceria ou resistência de segmentos sociais. ${ }^{12}$

Longe da instituição de um consenso, as experiências vigentes em vários contextos urbanos apontam processos como gentrificação, possibili-

11 Para o conceito de imaginário, ver, entre outros, Castoriadis, 1992.

12 Rubino (2009), refletindo sobre o conceito de "enobrecimento urbano", chama a atenção para a necessidade de incorporar dados etnográficos às análises, considerando a hipótese da diversidade de ocupações em cidades e as razões múltiplas pelas quais determinadas classes sociais vão morar no centro. 
dades de garantia de inclusão social, investimentos privados e múltiplas formas de ativação de um espaço considerado representativo da memória urbana. Trata-se de práticas políticas descontínuas que, não obstante contribuírem para a dinamização do espaço público, repõem o drama dos usos, das apropriações e dos conflitos vigentes na sociedade urbana contemporânea.

As tensões e pararadoxos da "revitalização" não constituem uma via de mão única que necessariamente transforma toda experiência de intervenção em mero pastiche. Na realidade, a visibilidade de práticas culturais e a incorporação de valor estético a zonas como Pelourinho, Centro de Recife, Centro Dragão do Mar em Fortaleza e Centro de São Luís são indiscutíveis. O desafio principal é o de tornar essas áreas expressão e congregação de sentidos coletivos urbanos partilhados. Não necessariamente avesso ou imune aos conflitos, mas aberto às negociações e percursos históricos que animam as pulsações da cidade.

(Recebido para publicação em julho de 2010) (Aceito em agosto de 2010)

\section{REFERÊNCIAS}

ARANTES, Antonio A. Paisagens paulistanas: transformações do espaço público. São Paulo: Ed. Unicamp, 2000.

Patrimônio cultural e cidade. In: FORTUNA, C.; LEITE, Proença R. (Org.). Plural de cidade: novos léxicos urbanos. Coimbra: Almedina/CES, 2009.

AUTHIER, Jean Yves. A gentrificação do bairro SaintGeorges em Lyon: a convivência de mobilidades diferenciadas. In: ZACHARIASEN, Catherine Bidou. De volta à cidade. São Paulo: AnnaBlume, 2003.

BARREIRA, Irlys Alencar F. Usos da cidade: conflitos simbólicos em torno da memória e imagem de um bairro. Análise Social. Lisboa, Instituto de Ciências Sociais da Universidade de Lisboa, ICS, v.42, 2007.

BARTHES, Roland. Mitologias. Rio de Janeiro: Bertrand, 1989. BERDOULAY, Vincent; PAES, Maria Tereza Duarte. Imagem e patrimonialização em planejamento urbano: Salvador (Bahia) e Bourdeaux em perspectiva. Revista Cidades: Imagens da cidade. São Paulo, UNESP, v.5, n.7, 2008.

CANCLINI, Nestor Garcia. Culturas híbridas, estratégias para entrar e sair da modernidade. São Paulo: EDUSP, 1998.

CASTORIADIS, Cornelius. A instituição imaginária da sociedade. Rio de Janeiro: Paz e Terra, 1992.

CARVALHO, Inaiá M.; ALMEIDA, Paulo Henrique; AZE-
VEDO, José Sérgio G. Dinâmica a metropolitana e estrutura social em Salvador. Tempo Social: revista de Sociologia. São Paulo, USP, v.13, n.2, 2001.

CERTEAU, Michel de. A invenção do cotidiano. Petrópolis: Vozes, 1994.

CHOAY, Françoise. A alegoria do patrimônio. São Paulo: UNESP, 2001.

CLAVER, Núria. Ciutat Vella de Barcelona: renovação ou gentrificação. In: ZACHARIASEN, Catherine Bidou. De volta à cidade: dos processos de gentrificação às políticas de "revitalização" dos centros urbanos. São Paulo: Annablume, 2003.

ESPIRITO SANTO, José Marcelo. Plano Municipal de Gestão: a revitalização do Centro Histórico de São Luís. In: VARGAS, Heliana Comin; CASTILHO, Ana Luisa H. (Org.) Intervenções em centros urbanos, objetivos, estratégias e resultados. São Paulo: Manole, 2006.

FORTUNA, Carlos Identidades, percursos, paisagens culturais. Lisboa: Celta, 1999.

GONDIM, Linda; FIGUEREDO, Ricardo; STUDART, Fontenele. Centro Dragão do Mar de Arte e Cultura: um projeto de requalificação da antiga área portuária de Fortaleza. In: VARGAS, Heliana; CASTILHO Ana Luísa (Org.) Intervenções em centros urbanos. São Paulo: Manole, 2006.

HABERMAS, Jürgen. Mudança estrutural na esfera pública. Rio de Janeiro: Tempo Brasileiro, 1984.

HOBSBAWM, Eric; RANGER, Terence. A invenção das tradições. Rio de Janeiro: Paz e Terra, 1997.

JACOBS, Jane. Morte e vida de grandes cidades. São Paulo: Martins Fontes, 2000.

KOWARICK, Lúcio Viver em risco. São Paulo: Editora 34. 2009.

LEITE, Rogério Proença. Contra-usos da cidade: lugares e espacos públicos na experiência urbana contemporânea. São Paulo: Editora Unicamp, 2007.

LIVRAMENTO, M. Turismo de $2^{\mathrm{a}}$ residência, europeus no Nordeste do Brasil. (Versão SBS) texto em versão PDF, s.d.

PEIXOTO, Paulo Liftings, peelings e outras plásticas. In: VAZ, Domingos (Org.) Cidade e território, identidades, urbanismo e dinâmicas transfronteiriças. Lisboa: Celta Editora, 2008.

PRETECEILLE, Edmond A evolução da segregação social e das desigualdades urbanas: o caso da metrópole parisiense. Cadernos CRH: revista Centro de Recursos Humanos da UFBA, Salvador, v.16, n.38, 2003.

RUBINO, Silvana Enobrecimento urbano. In: FORTUNA Carlos; LEITE, Rogério Proença (Org.) Plural de cidades: novos léxicos urbanos. Coimbra: Almedina/CES, 2009.

SENNETT, Richard O declínio do homem público, as tiranias da intimidade. São Paulo: Companhia das Letras, 1999.

SIMMEL, George. Fidelidade e gratidão e outros textos. Lisboa: Relógio D’Água, 2004.

VAINER, Carlos B. Pátria, empresa e mercadoria: notas sobre a estratégia discursiva do planejamento estratégico urbano. In: ARANTES, Otília; VAINER, Carlos; MARICATO, Ermínia. A cidade do pensamento único. Petrópolis: Vozes, 2000.

VASCONCELLOS L. M.; MELLO Maria Cristina M. Re atrás de, depois de... In: VARGAS, Heliana C.; CASTILHO Ana Luisa H. (Org.) Intervenções em centros urbanos, objetivos, estratégias e resultados. São Paulo: Manole, 2006.

VAZ, Domingos, M. Imagens da cidade e modos de comunicação. In: . (Org) Cidade e território, identidades, urbanismo e dinâmicas transfronteiriças, Lisboa: Celta. 2008. 


\section{PULSATIONS IN THE HEART OF THE CITY: scenarios for intervention in contemporary urban centers}

\section{Irlys Alencar F. Barreira Barreira}

In order to sort spaces and give back to urban centers their lost hegemonic role, contemporary urban policies have been seeking to foster different modes of intervention called "revitalization" or "requalification" The city, facing the valorization of its historical heritage, then becomes the object of architectural renovations and reforms, aimed at preservation, allowing for images and brands. The central objective of this paper is to reflect on the interventions in the contemporary metropolitan urban centers, including the most recent experiences conducted in Brazilian northeastern cities. This paper, less interested in making propositional assessments, analyzes symbolic concepts and conflicts that guide practices of "revitalization." The presence of various consumers of public space (tourists, residents, merchants etc.) and the controversies surrounding the cultural and economic investments will serve as a guide for the ideas in the text.

KEYWORDS: urban center, "revitalization”, public space, tourism metropolis.

\section{PULSATIONS EN PLEIN COEUR DE LA VILLE: Scénarios d'intervention dans les centres urbains contemporains}

\section{Irlys Alencar F. Barreira Barreira}

En vue d'organiser les espaces et de rendre aux centres urbains leur rôle hégémonique perdu, les politiques contemporaines cherchent à promouvoir divers modes d'intervention appelés "revitalisation" ou "requalification". La ville, penchée sur la valorisation de son patrimoine historique devient alors l'objet de travaux de rénovations et de réformes architecturales destinées à la préservation, donnant lieu à des images et à des marques. Réfléchir aux interventions qui ont lieu dans les centres urbains des métropoles contemporaines, y compris aux expériences plus récentes réalisées dans des villes du nord-est, constitue l'objectif principal de cet article. Plutôt que de vouloir faire des évaluations en vue de propositions, l'article analyse les conceptions et les conflits symboliques qui jalonnent les pratiques de "revitalisation". La présence de consommateurs diversifiés de l'espace public (touristes, habitants, commerçants, etc.) et les controverses établies concernant les investissements culturels et économiques serviront de jalon aux idées présentes dans le texte.

MotS-CLÉs: centre urbain, "revitalisation", espace public, tourisme, métropole.

Irlys Barreira - Doutora em Sociologia pela Universidade de São Paulo. Professora titular de Sociologia do Programa de Pós-Graduação em Sociologia da Universidade Federal do Ceará. Bolsista de produtividade em pesquisa do CNPq. Prioriza em suas pesquisas o estudo dos rituais, práticas políticas e valores sócio-culturais em diferentes contextos. É autora dos livros: O Reverso das Vitrines, Conflitos Urbanos e Cultura Política (Editora Rio Fundo, Rio de Janeiro, 1992), Chuva de papéis, ritos e símbolos de campanha eleitoral no Brasil (Editora Relume Dumará, Rio de Janeiro, 1998), Imagens ritualizadas, apresentação de mulheres em cenários políticos (Editora Pontes, São Paulo, 2008). Entre os trabalhos que enforcam mais especificamente o tema das cidades publicou: "Narrativas de Lisboa" (Almedina/Centro de Estudos Sociais - Coimbra, 2009); "Guias turísticos em Berlim" (Revista Tempo Social - Universidade de São Paulo, 2005) e "Narrativas do Olhar: Fortaleza em Cartões Postais” (Editora Universidade Federal de Sergipe, 2008). 